\title{
Hybrid e-Government Framework based on Datawarehousing and MAS for Data Interoperability
}

\author{
Barakat Oumkaltoum ${ }^{1}$, El beqqali Omar ${ }^{2}$, Chakir \\ Loqman $^{4}$ \\ Dept. of Computer Science \\ University Sidi Mohamed Ben Abdellah
}

Fes, Morocco

\author{
Ouksel $\mathrm{Aris}^{3}$ \\ Dept. of Computer Science \\ University of Illinois Chicago \\ Chicago, USA
}

\begin{abstract}
The exponential growth in technological innovation is driven in large part by the digitization of multiple domains and assumes environments of increasing data volumes, arriving at high velocity and variety. e-Government is one such domain that exploits current ICT innovations to improve the delivery of public services to its citizens, businesses, and other stakeholders This imposes to continuously maintain information on daily operations, activities, and assets as well as extensive profiles on citizens, institutions, and organizations. In addition, current centralized platform-based approaches suffer from the singlepoint-of-failure, which may result in data breaches and leakages, leading to the need for efficient robust mechanisms to ensure secure information sharing, data interoperability, and privacy. In this paper, we propose a business intelligence approach to design a data interoperability framework for e-governance based on data warehousing technology to improve transparency and data accessibility. We also present a hybrid data filtering mechanism, which relies both on the Extraction, Transformation, and Loading (ETL) process, and multi-agent technology to integrate data quality and data interoperability, and supports data transformation into human-readable format. Finally, the framework emphasizes the availability of materialized views to enable efficient execution of analytical queries directly on the large volumes of raw data in the data warehouse.
\end{abstract}

Keywords-e-Government; interoperability; multi-agent system; materialized views; datawarehouse; business intelligence

\section{INTRODUCTION}

E-government refers to the development of new public services and service delivery models that use digital technologies and government and citizen information systems assets.

While the development of government electronic services may have met resistance in the past due to the complexity of governmental policies and/or the lack of flexibility and capability of available technologies. This is no longer the case, in recent years, digital government architectures[1] have received special attention from researchers, embodying contemporary technologies and methodologies that will not only improve digital government performance, but also accelerate the pace of innovation by supporting the development of secure, autonomous, and transparent digital systems for the delivery of services and the management of rapidly and continuously increasing data volumes and varieties.
E-government provides a significant motivation for moving forward in the twenty-first century with higher-quality, more cost-effective government services and a stronger citizengovernment interaction. In Morocco, the e-government program is part of the "Maroc Numéric plan"[2] which was launched in 2013 as the program aims to improve government efficiency by increasing the quality-of-service delivery to customers and investors from all segments of society in an easy, quick, accurate, and efficient manner, to become a new type of government employee and government performance. Such a goal requires cross-administration coordination, which could be difficult to achieve at times.

Moroccan governments are on pace with their digital transformation. Some ministries were among the first to implement the transition, while others are still getting acquainted which is the case of the supreme council of justice, the presidency of the prosecution, and the ministry of justice, which are nevertheless among the most frequented, seem to be the least connected since this judicial system is one of the most important and complex in Morocco and is a key component of the e-government initiative, it is critical to solve one of the system's primary issues: separation of data management and data interoperability.

The interoperability affects an organization's performance and is a difficult problem for Moroccan judicial entities adopting big data systems. Because of the varied nature of the data they handle, the Heterogeneity in developing E-Gov, the quantity of Data, the Interaction between these Data, and the dynamicity of these Data. Finding trustworthy answers between data acquisition and data management is more challenging than ever, and strategic decision-making in the supreme Moroccan council of justice necessitates the utilization of numerous sources of information that involve all justice departments. Therefore, these challenges of interconnecting the government information system in general and justice information system particularly to public administrations require rapid access to essential data in an interoperable manner.

Adopting a business intelligence approach to design a data interoperability framework for e-governance based on warehousing technology seems to be the most suitable solution.

This paper is the continuation of our previous work (Big Data Interoperability for E-Governance[3]), the contribution of 
our work is to propose a data interoperability framework for egovernance based on warehousing technology and also to present a secure hybrid data filtering mechanism based on business intelligence approach and multi-agent system, considering widely adopted international standards for the exchange of government data. We show the benefits of such an approach in the area of usability, security, cost-reduction, and supporting e-government projects. The remainder of this paper is structured as follows. The background section presents the basic concepts that are necessary to understand our research problem. The second section presents the proposed framework and the study methods, followed by the section that describes our case study. The fourth section discusses the security and privacy aspect of the framework and the final section concludes by briefly presenting some of the study's implications for research and practice and future works.

\section{BACKGROUND}

In this section, we provide a brief overview of the related works and the basic concepts relevant to our proposed framework for the data interoperability of e-government system that are required to explain deeply this study in the article.

\section{A. Related Work}

Researchers have recommended several approaches such as citizen-centric, one-stop portal, social networking, and integrated e-government as viable ways to improve egovernment service delivery. These approaches increase egovernment service by offering an efficient service interface via which users may access services. Concerning the egovernance model, the majority of designs incorporate $\mathrm{G} 2 \mathrm{G}$ and $\mathrm{G} 2 \mathrm{C}$. G2B is used by just nine architectures out of fourteen. As a result, the most widely used e-governance models are $\mathrm{G} 2 \mathrm{G}$ and $\mathrm{G} 2 \mathrm{C}$. The Table I present a summary of existing e-government architecture from (2017-2020).

According to some research, SOA-based architecture is more appropriate for e-government since it uses componentbased applications that allow the composition of services from multiple service providers.

E-governments now-a-days require collaboration and integration of different public services entities to meet the varied requirements and desires of the end user[4]. Integration, coordination, and interaction inside and between various generated data in public sector organizations are among the requirements[5]. SOA approaches enable the reuse of services and thus the SOA layered model includes enterprise service bus (ESB) and service component architecture (ScA), which can increase interoperability in a diverse context[6].

Based on our early study[7] and the related work presented above, there is still limited work that provides a comprehensive architectural framework towards a real data interoperability for e-governance. Hence, this work proposes a hybrid and distributed e-government based on business intelligence and by using an easy and a simple architecture such as ETL mechanism and multi agent system to ensure interoperability among government services and private services. The proposed framework helps to reduce redundancy data provided by many agencies. Inter-department service sharing and reuse can also be improved thus it enhances decision making.

\section{B. E-Government Interoperability}

Because more administrations shift to internet operations and search for ways to improve their service provision and citizens' obligations, they are faced with bundling services, engaging with supply chains, opening up their data and developing innovative service options. Instead of only making use of their own internal data, machines are communicating to each other, and government entities now need to connect their systems to each other. Interoperability is one of the most important problems facing the government in terms of access to information from various information systems[8]. With the emergence of open data movements[9], Interoperability could become more important. When viewing interoperability as the ability of multiple systems and organizations to work together, there are different layers of abstraction. In addition to the structures and the level of organization, the following stages can be differentiated.

Organizational interoperability aims at ensuring that organizations cooperate in a harmonized manner[10]. Collaboration of networks and a single government will be accomplished in this way.

Interoperability of processes[11] refers to the ability of different business processes to collaborate, or "inter-operate. It aims at making separate managerial and policy-making systems work together. Cross-agency systems or supply chains may be generated in this manner.

Service interoperability[12] aims at developing new services or structures through the identification and composition of services and the exchange of these services. In this way, new services can be built from existing components.

Application interoperability refers to the capacity of an application to communicate with another application through the use of external services (e.g., middleware services). It seeks to combine programs with each other in such a manner that they function in collaboration, operating collectively as one.

Data interoperability[13] seeks to work together with multiple data structures in diverse query languages to exchange data from heterogeneous systems. It is concerned with the ability of systems and services that create, and consume data to have clear, shared expectations about the data's content, context, and meaning so data and information can be shared, merged and made accessible in this manner.

\section{Multi Agent System based ETL Approach}

A Multi-agent System (MAS) is a group of actors that interact between each other. In addition, each agent (actor) is able to deliver specific services and has a well-defined objective[23]. Each agent is able to autonomously execute multiple tasks and dispatch the result to a receiving actor (human or software). A MAS must adhere to the programming requirements established by the Intelligent Physical Agents Foundation[24]. 
TABLE I. COMPARISON OF EXISTING E-GOVERNMENT ARCHITECTURE

\begin{tabular}{|c|c|c|c|c|c|c|c|c|c|c|c|c|}
\hline \multirow[b]{2}{*}{ Architecture Name } & \multicolumn{3}{|c|}{ MODEL } & \multicolumn{6}{|c|}{ Architectural Pattern } & \multicolumn{3}{|c|}{$\begin{array}{l}\text { e-Gov } \\
\text { performance }\end{array}$} \\
\hline & $G 2 G$ & G2C & G2B & $S O A$ & $\boldsymbol{E A}$ & 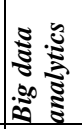 & $E D A$ & $M A S$ & $B \boldsymbol{I}$ & 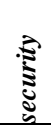 & పे & 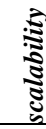 \\
\hline $\begin{array}{l}\text { Enterprise Integration of Employee Onboarding Process Using } \\
\text { Zachman Framework[14] }\end{array}$ & $\times$ & $\times$ & $\times$ & & $\times$ & & & & & $\times$ & $x$ & \\
\hline Collaboration vs. Choreography conformance in bpmn[15] & $\times$ & $\times$ & & & & & & & & & & \\
\hline Enterprise Architecture for e-government[16] & $\times$ & $\times$ & $\times$ & & $\times$ & & & & & $\times$ & $x$ & $\times$ \\
\hline $\begin{array}{l}\text { Census Web Service Architecture for e-Governance } \\
\text { Applications[17] }\end{array}$ & $\times$ & $\times$ & & $\times$ & & & & & & & & $\times$ \\
\hline $\begin{array}{l}\text { A Layered Architecture for Open Data: Design, implementation } \\
\text { and experiences [18] }\end{array}$ & $\times$ & $\times$ & & $\times$ & & & & & & & $x$ & $\times$ \\
\hline $\begin{array}{l}\text { A Model and Architecture for Building a Sustainable National } \\
\text { Open Government Data (OGD) Portal[19] }\end{array}$ & $x$ & $x$ & $\times$ & $\times$ & & & & & & $x$ & $x$ & $x$ \\
\hline Big Data Interoperability for E-Governance[3] & $\times$ & & & & & $x$ & & & & $\times$ & $x$ & $\times$ \\
\hline $\begin{array}{l}\text { Toward A Business Intelligence Model for challenges of } \\
\text { interoperability in egov system: Transparency, Scalability and } \\
\text { Genericity[5] }\end{array}$ & $x$ & $x$ & $x$ & $\times$ & & & & & $\times$ & $x$ & $x$ & $\times$ \\
\hline $\begin{array}{l}\text { Business Intelligence and EDA Based Architecture for } \\
\text { Interoperability of E-Government Data Services[6] }\end{array}$ & $\times$ & & $x$ & & & & $x$ & & $x$ & $\times$ & $x$ & $\times$ \\
\hline $\begin{array}{l}\text { A Feasible Community Cloud Architecture for Provisioning } \\
\text { Infrastructure as a Service in the Government Sector [4] }\end{array}$ & $x$ & & $x$ & $\times$ & & & & & & $x$ & & $\times$ \\
\hline $\begin{array}{l}\text { Cloud based architecture for interoperability of Data e- } \\
\text { government Services [7] }\end{array}$ & $\times$ & $\times$ & $x$ & & & $\times$ & & & & $\times$ & $x$ & $x$ \\
\hline $\begin{array}{l}\text { e-Government Architectural Planning Using Federal Enterprise } \\
\text { Architecture Framework in Purwakarta Districts } \\
\text { Government[20] }\end{array}$ & $\times$ & & $x$ & $x$ & & & & & & $\times$ & & \\
\hline $\begin{array}{l}\text { Preserving Privacy of Integrated e-Government Information } \\
\text { Architecture [21] }\end{array}$ & $\times$ & $x$ & & $\times$ & & & & & & & $x$ & \\
\hline $\begin{array}{l}\text { Business Intelligence and SOA Based Architecture for E- } \\
\text { government System Interoperability [22] }\end{array}$ & $\times$ & $\times$ & $\times$ & $\times$ & & & & & $\times$ & $\times$ & $x$ & $\times$ \\
\hline
\end{tabular}

Therefore, the purpose of using and combining a MAS and ETL (Extracting, Transforming and Loading) approach is developing an interoperability and data management system that would be able to have properties such as:

- Reactivity, which is defined as the ability to respond to user requests as well as the complexities of the human organization that characterizes the system's environment.

- Proactivity in anticipating user expectations or preventing problems in relation to the organization's goals.

- Flexibility to allow the system to adapt (addition of new agents, new roles for agents, etc.) in response to information and human organization evolution (capitalization and management of new types of knowledge, addition of new people in the organization, etc.)

\section{Overview of Data Warehousing Materialized View}

A materialized view is a database entity containing the query results. For example, it may be a local copy of remotely located data, or it may be a subset of a table's rows and/or columns, or it may be a description that uses an aggregate function[25].

Basically, materialized views are used to improve the efficiency of queries when they provide query data. For a faster execution, they can be used for reporting instead of a table.

Generally, data flows on a monthly, weekly, or regular basis from one or more online transaction processing (OLTP) databases into a data warehouse. Data is usually handled in a staging file before being added to the data warehouse. Data warehouses typically vary in scale from hundreds of gigabytes to a few terabytes. Usually, in a few very large fact tables, the vast majority of the data is held.

The creation of summaries is one technique employed in data warehouses to enhance performance. Summaries are particular types of aggregate views that by pre-calculating 
costly joins and aggregation operations prior to execution and storing the results in a database table, maximize query execution times. In this study we construct many summary tables, for instance, to include the number of judiciary cases by district and province or to determine for each district the cases and the rate of cases with a "judgment of innocence" by the courts under the judicial district of the Court of Appeal, in 2019

\section{BI DATA INTEROPERABILITY FRAMEWORK FOR E- GOVERNANCE}

Data warehouses are gradually being accessed through socalled information portals, which provide a standardized Web interface for OLAP, query, report generation, navigation, and data mining. In addition, portals offer coordinated access to a wide range of structured and unstructured data, particularly new information channels and digital libraries, that is stored outside of data warehouses. End users are given a personalized view of all data based on their business files and access rights.

This adds new interoperability requirements for the collaboration of different government portals repositories with other government warehouse specific repositories.

The construction of the data warehouses consists of implementing a series of data marts, each of which provides a dimensional view of a single business process. These data marts can be built around a set of shared dimensions[26].

In this paper, we discuss the data interoperability in the egovernment system based on data warehouses in more details. This discussion is based on a three-dimensional classification of the main types of metadata groups used by organizations as show in "Fig. 1", these data warehouse metadata groups are divided into users, business processes, and data dimensions. The "Fig. 2" illustrates an explanation of the three dimensions mentioned in the first figure, as well as the various relationships between them.

The "users" dimension, is where we make a clear distinction between internal and external users. The internal users are primarily responsible for the system's development and maintenance (e.g., managers, analysts, and others...).

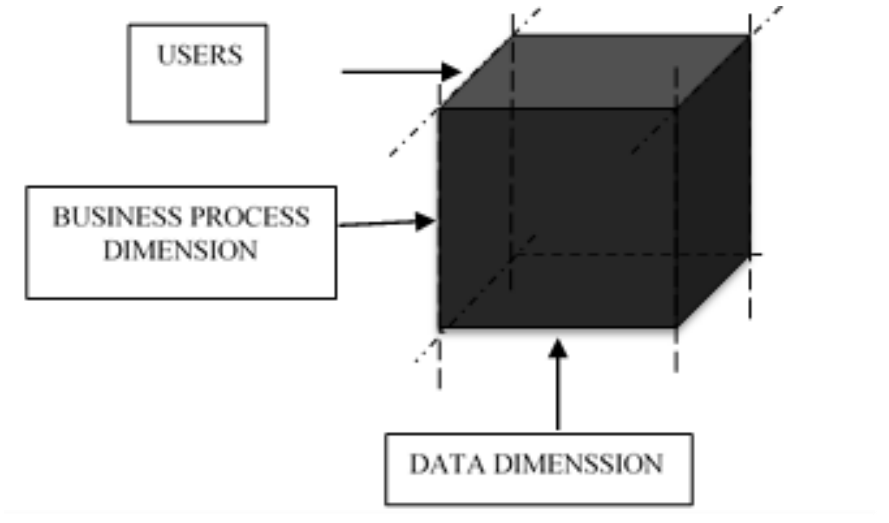

Fig. 1. Three-Dimensional Groups of Datawarehouse Metadata.

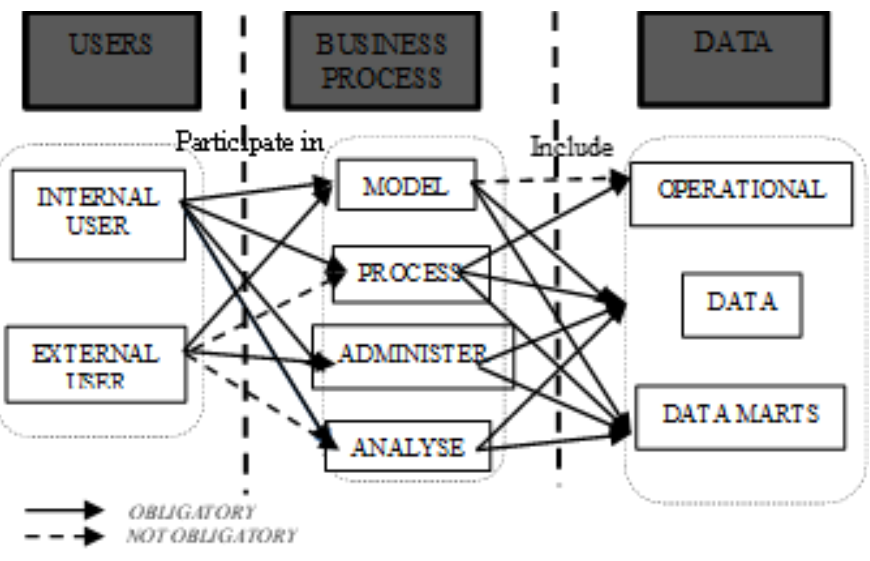

Fig. 2. Datawarehouse Metadata Classification Scheme.

The "business process" dimension is concerned with dynamic aspects and encompasses the metadata associated with the four major warehouse processes, namely model, processing, administration, and analysis. The model process is usually based on a modeling tool, which illustrates conceptual models, views, and other elements of the warehouse and data marts. It requires combining metadata obtained from different data sources. The processing process is strongly based on ETL tools [6]. The data warehouse and data marts must be provided with the data needed for analysis. It must execute data integration by transforming, cleansing, and mapping operational data into the data warehouse or data marts using rules and scripts. The administration process covers the management, maintenance, and tuning of the entire data warehouse environment except for the operational systems and finally, analysis processes are fully assisted by end-user specific data access tools for decision support, e.g., navigation, query and reporting, OLAP and data mining.

The "data" dimension organizes metadata into categories based on the information provided. We differentiate metadata associated with operational systems, data warehouses, and data marts based on warehouse architecture.

Our proposed Business Intelligence Data Interoperability Framework for e-governance (eGov-BDIF) is based on the business intelligence architecture. It addresses the challenges in terms of interoperability for data extraction, interoperability for reporting results and interoperability for data security and analysis. It develops advanced functionalities for better egovernance at different level as shown in "Fig. 3" (District, province, national). The aims of interoperability offering intuitive and straightforward public digital services to citizens and development of information sharing across different organizations and administration which represent a real complexity of cross-organizational collaboration. This is why the development of a common framework is very important for a data interoperability platform that could be scaled up and refined to elaborate robust solutions for different e-governance scenarios. 


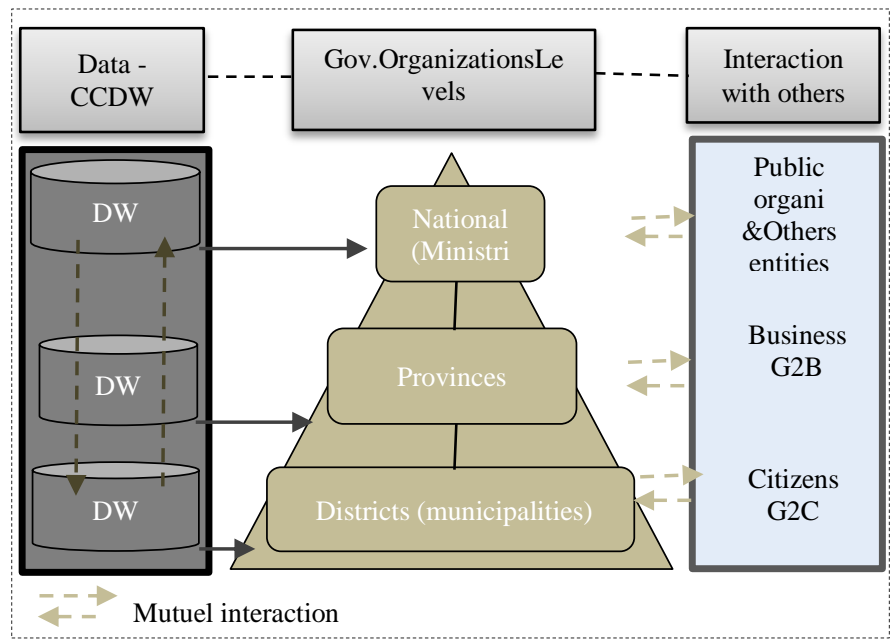

Fig. 3. Levels of Government Data Interoperability.

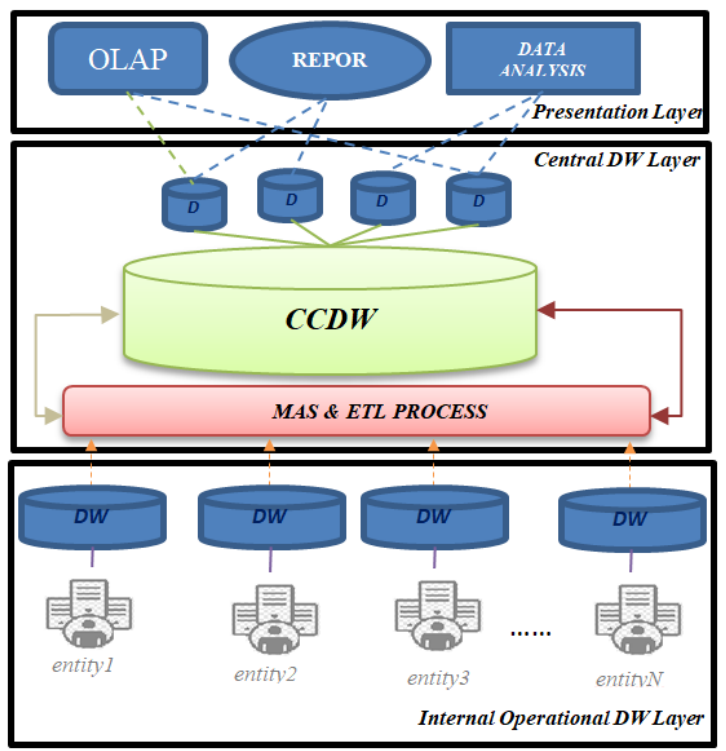

Fig. 4. Generic Architecture.

The eGov-BDIF is a comprehensive framework based on previous work[6]to address the government's need to maintain information about its daily operations, activities, assets and the details of its citizens, institutions and organizations secure for better e-governance in the collection, processing, storage, analysis and visualization of data stream .

Our framework illustrated in "Fig. 4" consists of an orchestration of various technological architectures that are represented as three complementary layers including presentation layer (or service access layer), Central Data warehousing \& MAS layer and internal operational DW layer that consist of the diverse data mart or small DW of the different entities. The presentation layer comprises of egovernment users and various devices for providing access, computing resource, and OLAP queries, reporting tools and data analysis.

The Central Data warehousing layer is meant to store different data sources such as PDFs, DOCs, contracts, and other files that are too huge to store or need to be deleted or altered in the future. With different access-management protocols, each level (district, regional and national) of the agency builds its own data warehouse. High-priority data is not available for general access and must be secured from misuse or unwanted access.

Therefore, for access and performance reason, an important technique to speed up analytical queries is used "the materialized view" which consist of pre-computing and materializing aggregations. Since intelligent agents are used today in all aspects of life to solve difficult challenges by distributing work. In the ETL [26]Multi Agent layer, we aim to integrate different agents that operate together and each agent executes various tasks based on the assigned role in the ETL process to minimize the error's occurrence. In fact, the addition of agents at different level of ETL process (data extraction level, data transformation and data loading level) minimizes the risk of error, improves performance and reliability and minimize execution time. Agents will invoke notifications when a problem occurs. A warning is created for missing or insignificant data. Each agent is assigned a particular function by adopting the standards for semantics and data format. In our case, the ETL-based agent method is used to help make the extraction, transformation and loading process effective, efficient and secure. In our system agents are grouped into four classes within a multi-agent system.

- Monitoring_Environment_Agent group1

- Extracting_Agent group2

- Transforming_Agent group3

- Loading group4

\section{CASE Study Description}

\section{A. E-government Data Warehousing Architecture for E- Justice}

The sharing of legal and judicial information[27] is one of the areas in which the e-government interoperability project can provide a level that cannot be matched by traditional mechanisms in obtaining this type of information, whether in terms of speed in reaching the required information, accuracy in arranging and classifying it, or being able to retrieve it When necessary, and also at the level of the vast amount of legal and judicial data that can be stored, downloaded, sent, searched and exploited [28].

The key entry point for the success of the e-government interoperability is the ease of access to justice by those seeking judicial services, including professionals, litigants and the general public, which comes through taking a set of measures, on top of which is the adoption of clear, smooth and accurately targeted electronic platforms, which are easy to distinguish between what was directed at specific groups and what was related to judicial, quasi-judicial or administrative services.

The aim of our eGov-BDIF in the case of the justice system is to help establishing legal and judicial security by providing an easy-to-use database of jurisprudence and various legislative texts. In addition, it enables the digital court to provide all the information related to a specific file to help make the right decision and thus, it enables the judicial process to speed up, 
especially for similar files, with the possibility of making sure to single out files that know specific peculiarities.

The scenario of our eGov-BDIF applied in the Moroccan ejustice system defines three main entities:

- MJ (Ministry of Justice)

- PMP (Presidency of the Public Prosecutor's Office)

- CSPJ (Supreme Council of the Judicial Power)

These three entities interact with each other through the Process Legal Case (PLC) "l'affaire juridique".

In fact, the process of a legal case involves a set of subbusiness processes (SBP).

$P L C=\sum_{i} S B P i$

Our approach defines for each sub-business process a set of data-marts and Data warehouses namely (DW_MJ, DW_PMP, DW_CSPJ) to build the common global DW related to the legal case process which in particular facilitate access to judicial services and better management of the judicial system and guarantee data interoperability between the three entities.

The common global DW "CGDW," is at the heart of our approach, it is made up of many physical data warehouses, such as DW_MJ, DW_PMP, DW_CSP, and each warehouse can be physically located on various servers and geographically in different locations, but these separate data warehouses function as a collection of materialized views by queries. We may have different data sources partitioned by regions (SDR), districts, or provinces, such as SDR-Casa, SDR-Marrakech, SDR-Rabat, SDR-Fes, etc. There will be a separate ETL process for each data source, which will be orchestrated by a multi-agent system to extract the source data to the corresponding target data warehouse.

Moreover, the most used sub-requests or other logical views are materialized in order to enable the access of the end user to information placed in various databases whenever he needs and wherever he is and to speed up the processing of requests on a vast volume of data processed in our data warehouses, so that the cost of processing requests is reduced with an optimum maintenance cost. Therefore, the "Fig. 5" present an instantiation of our proposed generic architecture detailed previously in "Fig. 4".

Withal, the main results of the application of our approach in the justice system are summarized as follows:

- Modernizing the judicial administration

- Improving the quality of services provided to users

- Facilitating access to them
- Improving the effectiveness of judicial performance on the horizon of achieving the digital court

- Simplifying and standardizing the judicial procedures, thus contributing to shortening deadlines and speeding up the procedures for resolving cases

- Contribute to speeding up the implementation of judicial decisions

- A smart environment by digitalizing judicial procedures, it contributes to the success of the zeropaper strategy and promotes environmental standards

- A smart court makes technologies at the service of judicial security

- A judicial facility that protects the rights of litigants and places the beneficiaries at the core of his mission

- Affordable justice system

- Effective, transparent and open services.

\section{DISCUSSION}

\section{A. Security and Privacy Aspect}

The security, confidentiality and privacy of the large information base envisaged are vital to the sustainability and efficiency of the data warehouse. Research on data warehouse security has allowed us to identify two classes of approaches:

- The approaches dealing with the security of operations: this work allows us to answer the questions who has the right of access and what does he have the right to?

- Approaches dealing with prevention against inference problems: they allow answering the question How to forbid a user to infer protected data from accessible data?

Obviously, the two classes of approaches complement each other in the security services they offer.

Nonetheless, many security risk concerns emerge from the implementation of ICT in Moroccan courts and imply simple security safeguards such as authentication, non-repudiation, transparency, integrity of data and intrusion into privacy. In order to be enforced, the justice system will need to consider and handle legal and non-legal security risks in the most reliable and successful way in order to excel in the data warehouse implementation. To avoid erroneous assumptions and to discourage profiling and stigmatization of some classes of people, the data warehouse should be used with caution. The Judiciary will need to determine the consistency of the data, establish quality assurance design \& create standards. This may involve identifying data consistency specifications, data processing procedures and validation of records, executing ETL logic tests and business rules. 


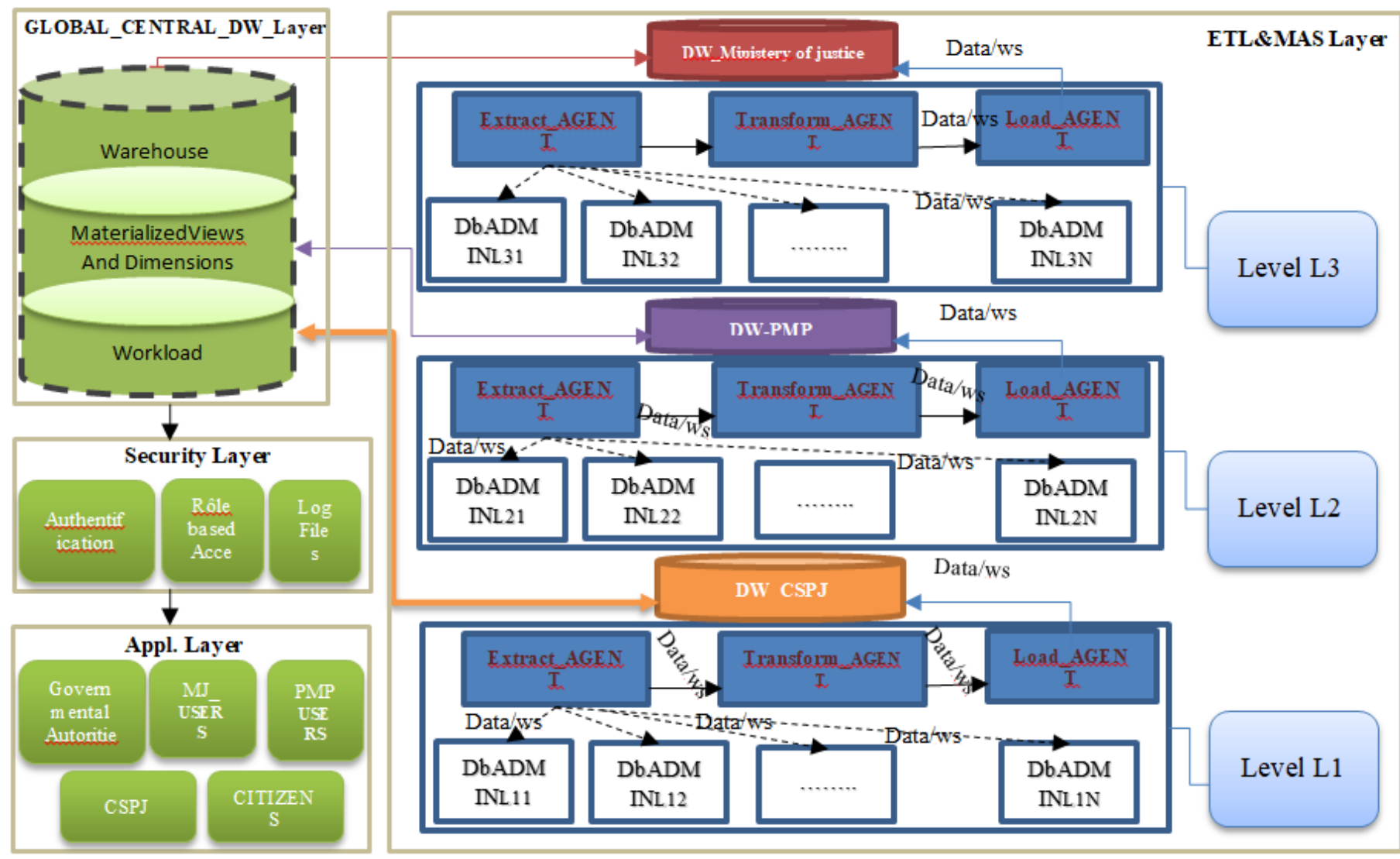

Fig. 5. E-justice Interoperability based on Datawarehousing Architecture and Multi Agent System.

\section{CONCLUSION AND FUTURE WORK}

Data warehousing is constantly being used for exploration and analysis to provide new information helping in decisionmaking. This work was intended to show how a hybrid approach of the ETL based on MAS and Data warehouses with Materialized views used to support the interoperability and the analysis of judicial data.

The present research is managed to simplify the data collection process by using the multi-agent ETL process to organize data loaded into the common global data warehouse. The data sources available in the Moroccan Judiciary system have been specifically outlined. The proposed Business Intelligence Data Interoperability Framework for e-governance has been developed. We also considered the query performance aspect by integrating and storing materialized views in the warehouses, which pre-aggregate the data, therefore avoiding access to the raw data and speeding up queries.

Finally, the implications of the project help the strategic choices of governments on the digital transformation within smart cities to support actors in co-creating organizational value, and societal well-being from business strategies and IT initiatives and foster the idea of environmentally sustainable egovernment and create a more environmentally conscious public sector.

The perspective expounds on the study of possible improvement and validation of our eGov-BDIF framework. The main object if that will constitute our future research axe is the development of advanced data warehousing systems by using a blockchain-based approach that constitute a crucial potential for improving the e-government business processes and data interoperability, providing transactional transparency and security in the value chain, and reducing operational cost.

\section{ACKNOWLEDGMENT}

We would like to thank all the people who have supported this work, as well as special thanks to Pr. Aris Ouksel, Professor of Information and Decision Sciences, from the University of Illinois at Chicago, USA for the support and assistance all along the project and to Dr. Chakir Loqman professor in the department of computer science at the university Sidi Mohamed Ben Abdellah of fes, Morocco for providing us the valuable data and statistics used in this research.

\section{REFERENCES}

[1] B. A. Baheer, D. Lamas, and S. Sousa, "A Systematic Literature Review on Existing Digital Government Architectures: State-of-the-Art, Challenges, and Prospects," Administrative Sciences, vol. 10, no. 2, Art. no. 2, Jun. 2020, doi: 10.3390/admsci10020025.

[2] A. Ennam, "The Emerging ICT Sphere in Morocco: Investigating the Feasibility and Usability of Massive Open Online Courses (MOOCs) -Surveying the Case of Ibn Tofail University EFLers," IISTE, vol. 60, 2017.

[3] E. B. M. Mahmoud, E. B. Omar, and A. M. Ouksel, "Big Data Interoperability for E-Governance," Journal of Computer Science, vol. 15, no. 10, pp. 1430-1438, Oct. 2019, doi: 10.3844/jcssp.2019.1430.1438. 
[4] K. Rodrigues de Castro, "A Feasible Community Cloud Architecture for Provisioning Infrastructure as a Service in the Government Sector," in Proceedings of the 20th Annual International Conference on Digital Government Research, Dubai United Arab Emirates, Jun. 2019, pp. 3540. doi: $10.1145 / 3325112.3325229$.

[5] B. Oumkaltoum, E. B. Mohamed Mahmoud, and E. B. Omar, "Toward A Business Intelligence Model for challenges of interoperability in egov system: Transparency, Scalability and Genericity," in 2019 International Conference on Wireless Technologies, Embedded and Intelligent Systems (WITS), Fez, Morocco, Apr. 2019, pp. 1-6. doi: 10.1109/WITS.2019.8723756.

[6] B. Oumkaltoum, E. I. Mohammed, E. B. M. Mahmoud, and E. B. Omar, "Business Intelligence and EDA Based Architecture for Interoperability of E-Government Data Services," in 2019 IEEE International Smart Cities Conference (ISC2), Casablanca, Morocco, Oct. 2019, pp. 402-407. doi: 10.1109/ISC246665.2019.9071769.

[7] O. Barakat, M. M. El Benany, and O. El Beqqali, "Cloud based architecture for interoperability of Data e-government Services," in 2019 Third International Conference on Intelligent Computing in Data Sciences (ICDS), Marrakech, Morocco, Oct. 2019, pp. 1-6. doi: 10.1109/ICDS47004.2019.8942293.

[8] E. C. D.-G. for Informatics, New European Interoperability Framework: Promoting Seamless Services and Data Flows for European Public Administrations. Publications Office, 2017.

[9] H. Masoumi, B. Farahani, and F. S. Aliee, "An Ontology-based Open Data Interoperability Approach for Cross-Domain Government Data Services," in 2020 25th International Computer Conference, Computer Society of Iran (CSICC), Tehran, Iran, Jan. 2020, pp. 1-8. doi: 10.1109/CSICC49403.2020.9050079.

[10] H. B. Sta, "Organisational structure for the e-government coordination and interoperability framework: a case study of Tunisia," EG, vol. 14, no. 1, p. 51, 2018, doi: 10.1504/EG.2018.089540.

[11] W. A. Khan, M. Hussain, K. Latif, M. Afzal, F. Ahmad, and S. Lee, "Process interoperability in healthcare systems with dynamic semantic web services," Computing, vol. 95, no. 9, pp. 837-862, Sep. 2013, doi: 10.1007/s00607-012-0239-3.

[12] F. Dzikrullah and M. A. Rinjani, "A framework design to develop integrated data system for smart e-government based on big data technology,” Bull.Socinf.The.App, vol. 1, no. 2, pp. 41-51, Dec. 2017, doi: 10.31763/businta.v1i2.26.

[13] K. Cenci, P. Fillottrani, and J. Ardenghi, "Government Data Interoperability: a Case Study from Academia," in Proceedings of the 10th International Conference on Theory and Practice of Electronic Governance - ICEGOV '17, New Delhi AA, India, 2017, pp. 625-628. doi: $10.1145 / 3047273.3047382$.

[14] W. Abbas, S. Ismail, H. Haron, W. Amalina, and W. A. Wan Hariri, "Enterprise Integration of Employee Onboarding Process Using Zachman Framework," International Journal of Engineering and Technology, vol. 7, pp. 46-51, Jan. 2018, doi: 10.14419/ijet.v7i4.31.23340.

[15] Corradini, Flavio, Morichetta, Andrea, Polini, Andrea, Re, Barbara, and Tiezzi, Francesco, "Collaboration vs. choreography conformance in BPMN," Logical Methods in Computer Science; Volume 16, p. Issue 4; 18605974, Oct. 2020, doi: 10.23638/LMCS-16(4:7)2020.

[16] R. Agarwal, V. Thakur, and R. Chauhan, "Enterprise Architecture for eGovernment," in Proceedings of the 10th International Conference on
Theory and Practice of Electronic Governance, New Delhi AA India, Mar. 2017, pp. 47-55. doi: 10.1145/3047273.3047330.

[17] A. Dutta, M. S. Devi, and M. Arora, "Census Web Service Architecture for e-Governance Applications," in Proceedings of the 10th International Conference on Theory and Practice of Electronic Governance, New Delhi AA India, Mar. 2017, pp. 1-4. doi: 10.1145/3047273.3047390.

[18] G. Cordasco, D. Malandrino, D. Pirozzi, V. Scarano, and C. Spagnuolo, "A Layered Architecture for Open Data: design, implementation and experiences," in Proceedings of the 11th International Conference on Theory and Practice of Electronic Governance, Galway Ireland, Apr. 2018, pp. 371-381. doi: 10.1145/3209415.3209466.

[19] L. L. Idowu, I. I. Ali, and U. G. Abdullahi, "A Model and Architecture for Building a Sustainable National Open Government Data (OGD) Portal," in Proceedings of the 11th International Conference on Theory and Practice of Electronic Governance, Galway Ireland, Apr. 2018, pp. 352-362. doi: 10.1145/3209415.3209454.

[20] M. Defriani and M. G. Resmi, "E-Government Architectural Planning Using Federal Enterprise Architecture Framework in Purwakarta Districts Government," in 2019 Fourth International Conference on Informatics and Computing (ICIC), Semarang, Indonesia, Oct. 2019, pp. 1-9. doi: 10.1109/ICIC47613.2019.8985819.

[21] H. AlAbdali, M. AlBadawi, and M. Sarrab, "Preserving Privacy of Integrated E-Government Information: Architecture Approach," in 2019 2nd IEEE Middle East and North Africa Communications Conference (MENACOMM), Manama, Bahrain, Nov. 2019, pp. 1-5. doi: 10.1109/MENACOMM46666.2019.8988522.

[22] O. Barakat and O. El beqqali, "Business Intelligence and SOA Based Architecture for E-government System Interoperability," in Proceedings of the 13th International Conference on Intelligent Systems: Theories and Applications, New York, NY, USA, Sep. 2020, pp. 1-5. doi: 10.1145/3419604.3419790.

[23] Z. Elaggoune, R. Maamri, and I. Boussebough, "A Multi-Agent Framework for Multi-Criteria Business Intelligence driven Smart Data in a Big Data Environment," p. 6.

[24] V. Gancheva, "SOA Based Multi-Agent Approach for biological data searching and integration," International Journal of Biology and Biomedical Engineering, vol. 13, 2019.

[25] A. Gosain and K. Sachdeva, "A Systematic Review on Materialized View Selection," in Proceedings of the 5th International Conference on Frontiers in Intelligent Computing: Theory and Applications, vol. 515, S. C. Satapathy, V. Bhateja, S. K. Udgata, and P. K. Pattnaik, Eds. Singapore: Springer Singapore, 2017, pp. 663-671. doi: 10.1007/978981-10-3153-3_66.

[26] D. Dzemydienè, S. Maskeliūnas1, And V. Radzevičius1, "An Approach Of Ensuring Interoperability Of Multi-Dimensional Data Warehouses For Monitoring Of Water Resources," Journal Of Environmental Engineering And Landscape Management, 2021.

[27] G. Lupo and J. Bailey, "Designing and Implementing e-Justice Systems: Some Lessons Learned from EU and Canadian Examples," Laws, vol. 3, no. 2, pp. 353-387, Jun. 2014, doi: 10.3390/laws3020353.

[28] G. Lupo and M. Velicogna, "Making EU Justice Smart? Looking into the Implementation of New Technologies to Improve the Efficiency of Cross Border Justice Services Delivery," in Smart Technologies for Smart Governments, vol. 24, M. P. Rodríguez Bolívar, Ed. Cham: Springer International Publishing, 2018, pp. 95-121. doi: 10.1007/978-3-31958577-2_6. 